\title{
Fungal arthritis with adjacent osteomyelitis caused by Candida pelliculosa: a case report
}

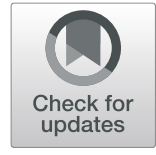

\author{
Kwang Yun Song ${ }^{1}$, Chulmin Park ${ }^{2}$, Ji-Hyun Byun ${ }^{2}$, Hye-Sun Chun², Jung-Hyun Choi ${ }^{2,3}$, Eun Hee Han ${ }^{4}$, \\ Seung Ok Lee ${ }^{4}$, Yeonjeong Jeong ${ }^{3,5}$, Youn Jeong Kim ${ }^{3,5}$ and Si-Hyun Kim ${ }^{2,3,5^{*}}$ (D)
}

\begin{abstract}
Background: Candida sp. osteoarticular infection is rare and most often due to hematogenous seeding during an episode of candidemia in immunocompromised patients. However, the diagnosis can be delayed in patients with subtle symptoms and signs of joint infection without a concurrent episode of candidemia.

Case presentation: A 75-year-old woman presented with a three-year history of pain and swelling of the left knee. Candida pelliculosa was detected from the intraoperative tissue when the patient had undergone left total knee arthroplasty 32 months ago, but no antifungal treatment was performed. One year after the total knee arthroplasty, C. pelliculosa was repeatedly isolated from the left knee synovial fluid and antifungal treatment comprising amphotericin B deoxycholate and fluconazole was administered. However, joint infection had extended to the adjacent bone and led to progressive joint destruction. The patient underwent surgery for prosthesis removal and received prolonged antifungal treatment with micafungin and fluconazole.
\end{abstract}

Conclusions: This case shows that C. pelliculosa, an extremely rare non-Candida albicans sp., can cause fungal arthritis and lead to irreversible joint destruction owing to delayed diagnosis and treatment.

Keywords: Arthritis, Osteomyelitis, Candida, Micafungin

\section{Background}

Infectious arthritis may be caused by various pathogens including bacteria, viruses, fungi, and parasites. Although bacterial arthritis is the most common joint infection, Candida, Cryptococcus, and Aspergillus species and other molds are capable of causing fungal arthritis, particularly in immunocompromised or critically ill patients $[1,2]$. Fungal arthritis is an uncommon but challenging clinical condition, and Candida spp. are the most common cause.

Candida pelliculosa is a rare human pathogen. It is a ubiquitous yeast usually found in fruits, grains, soil,

\footnotetext{
* Correspondence: ksihyun@catholic.ac.kr

${ }^{2}$ Vaccine Bio Research Institute, College of Medicine, The Catholic University of Korea, Seoul, Republic of Korea

${ }^{3}$ Department of Internal Medicine, College of Medicine, The Catholic University of Korea, Seoul, Republic of Korea

Full list of author information is available at the end of the article
}

plants, and warm-blooded animals. The first case of invasive infection by this pathogen in humans was reported in 1953, and since then there have been a few cases of fungemia, endophthalmitis, and meningitis caused by C. pelliculosa [3-6]. Thus far, cases of osteoarticular infection caused by $C$. pelliculosa are extremely rare [7]. Herein, we report a case of fungal arthritis with adjacent osteomyelitis caused by C. pelliculosa in an elderly patient with no underlying immunosuppressive condition.

\section{Case presentation}

A 75-year-old woman presented with a 3-year history of pain and swelling of the left knee, with the pain particularly intensifying over the past month. Because oral medications and intra-articular injections of unidentified agents did not help improve her symptoms, the patient had undergone left total knee arthroplasty at a local

(c) The Author(s). 2020 Open Access This article is licensed under a Creative Commons Attribution 4.0 International License, which permits use, sharing, adaptation, distribution and reproduction in any medium or format, as long as you give appropriate credit to the original author(s) and the source, provide a link to the Creative Commons licence, and indicate if changes were made. The images or other third party material in this article are included in the article's Creative Commons licence, unless indicated otherwise in a credit line to the material. If material is not included in the article's Creative Commons licence and your intended use is not permitted by statutory regulation or exceeds the permitted use, you will need to obtain permission directly from the copyright holder. To view a copy of this licence, visit http://creativecommons.org/licenses/by/4.0/ The Creative Commons Public Domain Dedication waiver (http://creativecommons.org/publicdomain/zero/1.0/) applies to the data made available in this article, unless otherwise stated in a credit line to the data. 
hospital 32 months ago. C. pelliculosa was isolated from the tissue collected by intraoperative biopsy, but no antifungal treatment was initiated. One year after the total knee arthroplasty, C. pelliculosa was repeatedly isolated from the left knee synovial fluid, and the patient received the following antifungal agents for 9 weeks: intravenous amphotericin B deoxycholate $(0.5$ $\mathrm{mg} / \mathrm{kg} /$ day) for 4 weeks, then intravenous fluconazole $(6 \mathrm{mg} / \mathrm{kg} /$ day $)$ for 3 weeks, followed by oral fluconazole $(4 \mathrm{mg} / \mathrm{kg} /$ day $)$ for 2 weeks. However, progressive bone loss around the prosthetic components was seen on follow-up radiographs, and the patient was referred to a tertiary hospital. The patient had no other significant medical history.

At the time of admission, the patient's vital signs were stable, with blood pressure of $130 / 70 \mathrm{mmHg}$, pulse rate of 76 beats/minute, and body temperature of $36.8{ }^{\circ} \mathrm{C}$. On physical examination, there was an erythematous, swollen, warm, and tender lesion measuring $3 \mathrm{~cm} \times 5 \mathrm{~cm}$ on the anterolateral aspect of the left knee. Laboratory tests revealed a white blood cell count of 5460 cells $/ \mathrm{mm}^{3}$ with $50.7 \%$ neutrophils, erythrocyte sedimentation rate of 49 $\mathrm{mm} / \mathrm{h}$ (reference range $0-20$ ), and C-reactive protein of $15.73 \mathrm{mg} / \mathrm{L}$ (reference range $0-5$ ). All other blood chemistry results were within the reference ranges. Radiography of the left knee at admission showed loosening of prosthesis owing to bone resorption of the proximal tibia and distal femur (Fig. 1). Synovial fluid analysis revealed the following: white blood cell count of 608 cells $/ \mathrm{mm}^{3}$ (neutrophils $54 \%$, lymphocytes $22 \%$, macrophages $24 \%$ ), red blood cell count of 2737 cells $/ \mathrm{mm}^{3}$, glucose of $7 \mathrm{mg} /$ $\mathrm{dL}$, protein of $5.9 \mathrm{~g} / \mathrm{dL}$, and lactate dehydrogenase of $6547 \mathrm{IU} / \mathrm{L}$. Magnetic resonance imaging demonstrated destruction of the lateral tibial condyle, filled with granulation tissue extending to adjacent diffuse cellulitis with a large abscess on the anterolateral aspect of the left knee (Fig. 2). Routine bacterial culture of the synovial fluid using the Vitek 2 microbial identification system (BioMerieux, France) was positive for C. pelliculosa. Results of other microbiological tests including acid-fast bacilli staining, mycobacterial culture, and realtime PCR assay to detect Mycobacterium tuberculosis and non-tuberculous mycobacteria were all negative.

The isolate was confirmed as C. pelliculosa using internal transcribed spacer 1 ( $5^{\prime}$-TCCGTAGGTGAACC TGCGG- $\left.3^{\prime}\right)$ and 4 (5' ${ }^{\prime}$-TCCTCCGCTTATTGATATG$3^{\prime}$ ) region PCR, followed by sequencing. Minimum inhibitory concentrations for antifungal agents were determined according to the Clinical and Laboratory Standards Institute guidelines by broth microdilution, and the results are as follows: $0.125 \mathrm{mg} / \mathrm{L}$ for amphotericin $\mathrm{B}, 0.06 \mathrm{mg} / \mathrm{L}$ for anidulafungin, $0.125 \mathrm{mg} / \mathrm{L}$ for caspofungin, $1 \mathrm{mg} / \mathrm{L}$ for fluconazole, $0.06 \mathrm{mg} / \mathrm{L}$ for micafungin, and $0.06 \mathrm{mg} / \mathrm{L}$ for voriconazole.
After 2 weeks of micafungin therapy ( $100 \mathrm{mg} /$ day), the patient underwent surgery for prosthesis removal with debridement of soft tissue and bone, total synovectomy, and placement of an antibiotic-impregnated spacer. Operative findings showed infected granulation tissue in the whole joint space and bony fistula, extending to the anterolateral aspect of the lateral tibial component (Fig. 3). Histopathology showed acute and chronic inflammation with fibrinous exudation and necrotic debris. There was no isolated pathogen from intraoperative specimens. After the surgery, the patient was given micafungin for 4 weeks, followed by oral fluconazole ( 6 $\mathrm{mg} / \mathrm{kg} /$ day). There were no signs of infection around the left knee, and the patient was discharged from the hospital. New prosthesis was implanted 12 months after the stage 1 procedure, and the patient is on taking oral fluconazole $(6 \mathrm{mg} / \mathrm{kg} /$ day $)$ and is scheduled to maintain for up to 3 months after the stage 2 procedure (Fig. 4). The prolonged antifungal therapy with oral fluconazole was well tolerated, and the patient was very compliant with the treatment.

\section{Discussion and conclusions}

In this case, it is presumed that C. pelliculosa was inoculated at the time of intra-articular injection. However, $C$. pelliculosa isolated from the synovial fluid was initially disregarded as contamination in the patient who had complaints of chronic joint pain and swelling. After one year, C. pelliculosa was repeatedly identified from the same joint and antifungal treatment was initiated at a suboptimal dose, but the joint infection had extended to the adjacent bone, and eventually, prosthesis removal and prolonged use of antifungal agents were required.

With recent advances in medical technology, the incidence of Candida sp. osteoarticular infection has been steadily increasing over the last two decades [8-10]. Candida sp. osteoarticular infection is more often observed in immunocompromised hosts but may sometimes occur in normal hosts. Risk factors for Candida sp. osteoarticular infection include abdominal or orthopedic surgery, alcohol abuse, central venous catheters, diabetes mellitus, hemodialysis, hyperalimentation, immunosuppressive therapy, intravenous drug use, malignancy, prolonged use of broad-spectrum antimicrobials, and trauma or open wounds $[1,8,10]$. In most cases, Candida sp. osteoarticular infection results from hematogenous dissemination. It can also occur from direct inoculation during trauma, surgery, or intra-articular injections. In the former cases, symptoms associated with joint inflammation and fever may arise acutely. In contrast, patients with the latter cases, such as this case, often complain of an insidious onset of joint pain with minimal systemic manifestations. It is therefore not easy to diagnose Candida sp. osteoarticular infection early in 

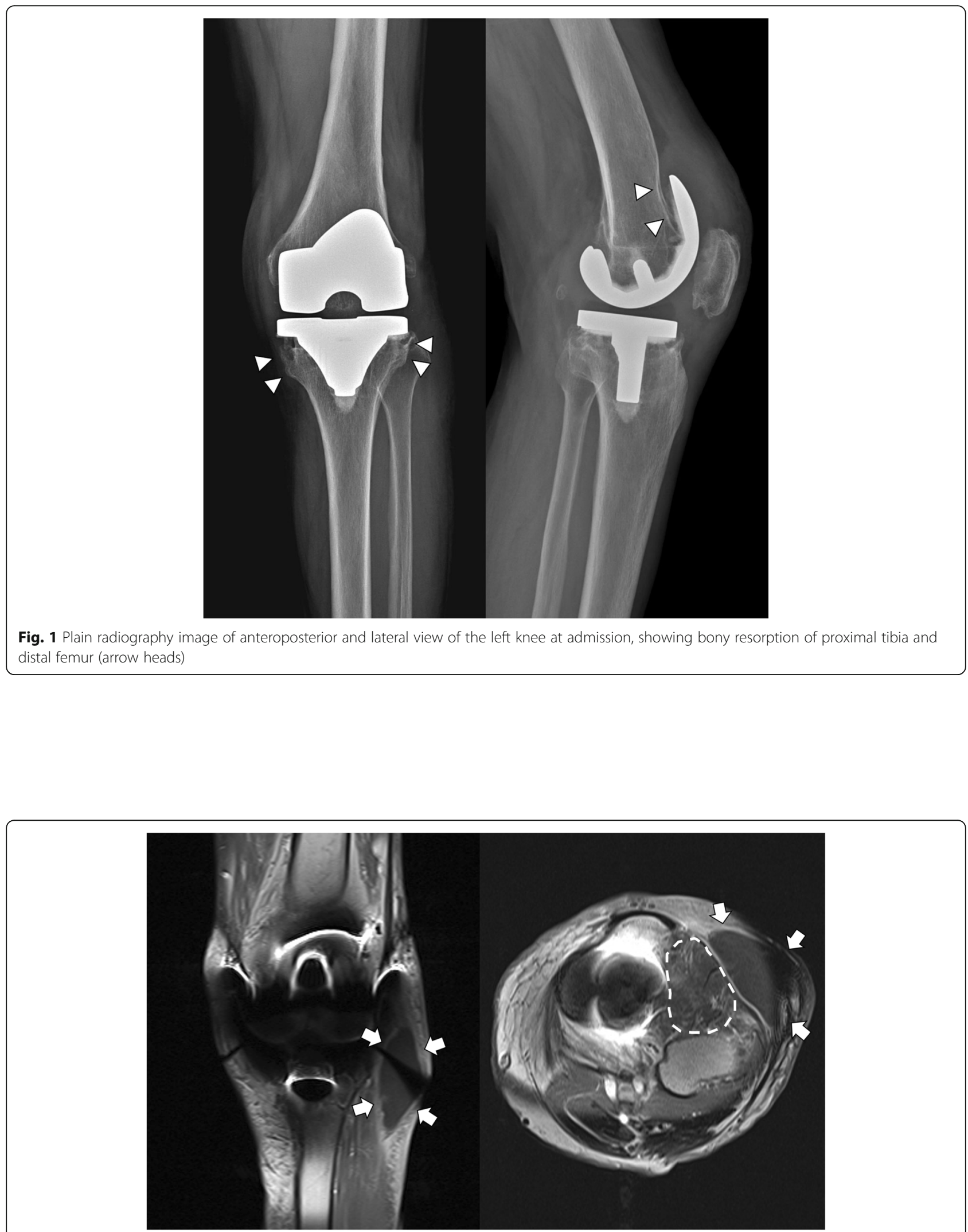

Fig. 2 Contrast-enhanced T1-weighted magnetic resonance images of the left knee, showing destruction of the lateral tibial condyle filled with granulation tissue (dotted line) extending to adjacent subcutaneous abscess lesion (arrows) on the anterolateral aspect of the knee joint 


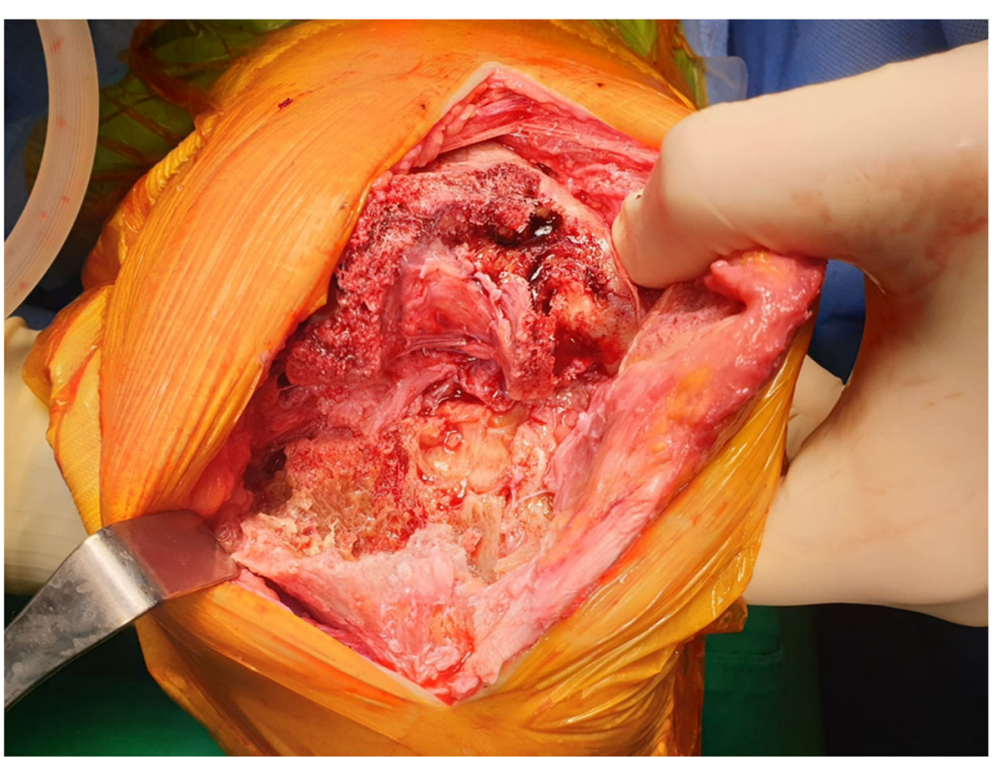

Fig. 3 Operative findings of the left knee. Using midline skin incision and medial parapatellar approach to expose the left knee joint, femoral and tibial components of the prosthesis were removed, exposing infected granulation tissue and bone resorption mainly on the lateral tibial and femoral condyles

patients who do not have a recent or current episode of candidemia at the time of presentation as well as a risk factor for Candida sp. osteoarticular infection. Patients with subtle symptoms and signs of joint infection without fever often experience delayed diagnosis. Delayed diagnosis of Candida sp. osteoarticular infection can lead to progressive joint destruction with irreversible loss of articular function.

There is no specific symptom or test for Candida sp. osteoarticular infection. The diagnosis can be established by culture of the synovial fluid. The most common species is Candida albicans, followed by Candida tropicalis,

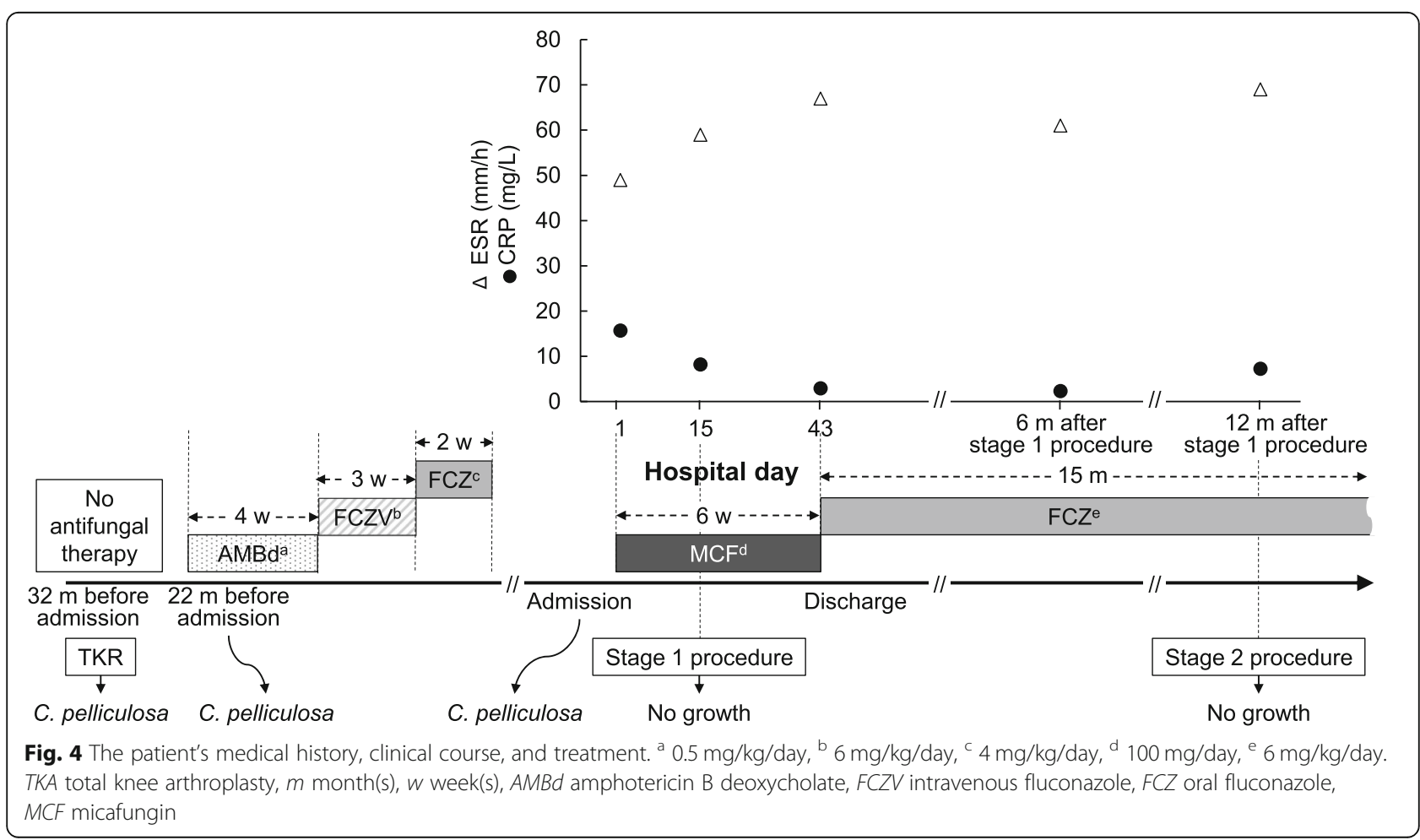


and Candida parapsilosis. C. pelliculosa (anamorph form), formerly known as Pichia anomala (teleomorph form), is a heterothallic, ascomycetous yeast. The recent taxonomic developments of yeasts have renamed $P$. anomala as Wickerhamomyces anomalus based on phylogenetic analysis on multigene sequences [11]. It is a rare, opportunistic pathogen with low virulence that exists widely in the environment. However, it has been recently reported as an emerging non-Candida albicans sp. associated with various forms of invasive infections [3-6]. In addition, there are several reports of nosocomial outbreaks of fungemia caused by $C$. pelliculosa in neonatal or pediatric intensive care units [12-14]. The major concern regarding treatment of infections caused by the rare yeast species is selecting optimal antifungal agents and dosages because there are currently no established breakpoints for these species. Although the data are limited, treatment with amphotericin B or fluconazole for C. pelliculosa infections has been reported to be successful [12-14]. In a more recent study of a nosocomial outbreak of fungemia caused by C. pelliculosa, the authors suggested echinocandin as an effective option for the treatment of C. pelliculosa infection [6].

For Candida sp. arthritis, fluconazole for 6 weeks or echinocandin (micafungin, caspofungin, or anidulafungin) for 2 weeks, followed by fluconazole for at least 4 weeks is recommended [15]. However, the duration of antifungal therapy should be extended to 6-12 months for Candida sp. osteomyelitis [15]. For Candida sp. arthritis of native joints, adequate drainage is recommended [15]. However, in one study, only $36 \%$ of patients underwent adjunctive surgical intervention including drainage, irrigation, debridement, and amputation, and $62 \%$ of patients were treated with medical therapy alone [10]. In most cases with Candida $s p$. osteomyelitis, both surgical intervention and prolonged antifungal therapy are warranted to eradicate the infection [16].

Candida sp. prosthetic joint infection is more difficult to treat. The formation of Candida biofilms on both human tissues and prosthetic materials has been studied extensively and is thought to contribute to treatment failure [17-19]. For the treatment of Candida sp. prosthetic joint infection, a two-stage arthroplasty exchange is the preferred surgical approach for eradicating infection and preserving joint function $[15,20]$. Two-stage arthroplasty exchange is composed of two surgeries: removal of all prosthetic materials (stage 1), and reimplantation of a new prosthesis usually 3 to 6 months later (stage 2). Antifungal therapy should be continued for at least 12 weeks after stage 1 surgery and for at least 6 weeks after stage 2 surgery. The interval between the two surgeries is not yet established.

A rare Candida sp. could be a causative organism of osteoarticular infection, especially in patients with a prior history of intra-articular injections. Even a single colony of Candida on synovial fluid should be considered as pathogenic, and the patient should receive the optimized antifungal therapy by selecting the appropriate drug, dosage, and duration. A high index of suspicion is required to establish the correct diagnosis and successful treatment to prevent irreversible joint destruction and preserve articular function.

\section{Acknowledgments \\ We are also thankful to the entire Division of Clinical Microbiology in Incheon Mary's Hospital for their effort in collecting isolates. This case report was presented in a poster session at the 9th Trends in Medical Mycology held on 11-14 October 2019, Nice, France.}

\section{Authors' contributions}

SHK and JHC designed the study. EHH, SOL, CP, JHB and HSC performed the research experiments. YJ and YJK were responsible for the data collection and literature search. SHK and KYS were major contributors in writing the manuscript. All authors read and approved the final manuscript.

\section{Funding}

The authors wish to acknowledge the financial support of the Catholic Medical Center Research Foundation made in the program year of 2017. The financial supporter had no role in the design of study and collection, analysis, and interpretation of data and in writing the manuscript.

Availability of data and materials

The data used during the current study are available from the corresponding author on reasonable request.

\section{Ethics approval and consent to participate}

The study was approved by the Incheon St. Mary's Hospital Institutional Review Board of the Catholic University of Korea (approved No. OC20ZASI0022).

\section{Consent for publication}

The patient provided written informed consent for her personal or clinical details with any identifying images to be published in this study.

\section{Competing interests}

The authors declare that they have no competing interests.

\section{Author details}

${ }^{1}$ Department of Orthopedic Surgery, College of Medicine, The Catholic University of Korea, Seoul, Republic of Korea. ${ }^{2}$ Vaccine Bio Research Institute, College of Medicine, The Catholic University of Korea, Seoul, Republic of Korea. ${ }^{3}$ Department of Internal Medicine, College of Medicine, The Catholic University of Korea, Seoul, Republic of Korea. ${ }^{4}$ Department of Laboratory Medicine, College of Medicine, The Catholic University of Korea, Seoul, Republic of Korea. ${ }^{5}$ Division of Infectious Diseases, Department of Internal Medicine, Incheon St. Mary's Hospital, College of Medicine, The Catholic University of Korea, 56 Dongsu-ro, Bupyeong-gu, Incheon 403-720, Republic of Korea.

Received: 16 April 2020 Accepted: 17 June 2020

Published online: 22 June 2020

\section{References}

1. Bariteau JT, Waryasz GR, McDonnell M, Fischer SA, Hayda RA, Born CT. Fungal osteomyelitis and septic arthritis. J Am Acad Orthop Surg. 2014;22(6): 390-401.

2. Henry MW, Miller AO, Walsh TJ, Brause BD. Fungal musculoskeletal infections. Infect Dis Clin N Am. 2017:31(2):353-68.

3. Ratcliffe L, Davies J, Anson J, Hales S, Beeching NJ, Beadsworth MB. Candida pelliculosa meningitis as an opportunistic infection in HIV: the first reported case. Int J STD AIDS. 2011;22(1):54-6. 
4. Kang SJ, Jang MO, Jang HC, Jung SI, Shin JH, Park KH. A case of Candida pelliculosa prosthetic valve endocarditis treated with anidulafungin and valve replacement. Infect Chemother. 2012;44(6):499-503.

5. Esgin $\mathrm{H}$, Bulut $\mathrm{E}$, Orum C. Candida pelliculosa endophthalmitis after cataract surgery: a case report. BMC Res Notes. 2014;7:169.

6. Jung J, Moon YS, Yoo JA, Lim JH, Jeong J, Jun JB. Investigation of a nosocomial outbreak of fungemia caused by Candida pelliculosa (Pichia anomala) in a Korean tertiary care center. J Microbiol Immunol Infect. 2018; 51(6):794-801

7. Choi SW, Lee TJ, Kim MK, Lee M, Jung JH. A case of fungal arthritis caused by Hansenula anomala. Clin Orthop Surg. 2010;2(1):59-62

8. Silveira LH, Cuellar ML, Citera G, Cabrera GE, Scopelitis E, Espinoza LR. Candida arthritis. Rheum Dis Clin N Am. 1993;19(2):427-37.

9. Trofa D, Gacser A, Nosanchuk JD. Candida parapsilosis, an emerging fungal pathogen. Clin Microbiol Rev. 2008;21(4):606-25.

10. Gamaletsou MN, Rammaert B, Bueno MA, Sipsas NV, Moriyama B, Kontoyiannis DP, et al. Candida arthritis: analysis of 112 pediatric and adult cases. Open Forum Infect Dis. 2016;3(1):ofv207.

11. Kurtzman CP. Phylogeny of the ascomycetous yeasts and the renaming of Pichia anomala to Wickerhamomyces anomalus. Antonie Van Leeuwenhoek. 2011;99(1):13-23.

12. da Silva CM, de Carvalho Parahym AM, Leão MP, de Oliveira NT, de Jesus Machado Amorim R, Neves RP. Fungemia by Candida pelliculosa (Pichia anomala) in a neonatal intensive care unit: a possible clonal origin. Mycopathologia. 2013;175(1-2):175-9

13. Kalkanci A, Dizbay M, Turan O, Fidan I, Yalçin B, Hirfanoğlu I, et al. Nosocomial transmission of Candida pelliculosa fungemia in a pediatric intensive care unit and review of the literature. Turk J Pediatr. 2010; 52(1):42-9.

14. Lin HC, Lin HY, Su BH, Ho MW, Ho CM, Lee CY, et al. Reporting an outbreak of Candida pelliculosa fungemia in a neonatal intensive care unit. J Microbiol Immunol Infect. 2013;46(6):456-62.

15. Pappas PG, Kauffman CA, Andes DR, Clancy CJ, Marr KA, Ostrosky-Zeichner $L$, et al. Clinical practice guideline for the management of candidiasis: 2016 update by the Infectious Diseases Society of America. Clin Infect Dis. 2016; 62(4):e1-50

16. Gamaletsou MN, Kontoyiannis DP, Sipsas NV, Moriyama B, Alexander E, Roilides E, et al. Candida osteomyelitis: analysis of 207 pediatric and adult cases (1970-2011). Clin Infect Dis. 2012;55(10):1338-51.

17. Bujdakova H. Management of Candida biofilms: state of knowledge and new options for prevention and eradication. Future Microbiol. 2016;11(2): 235-51

18. Cavalheiro M, Teixeira MC. Candida Biofilms: threats, challenges, and promising strategies. Front Med (Lausanne). 2018;5:28.

19. Vitális E, Nagy F, Tóth Z, Forgács L, Bozó A, Kardos G, et al. Candida biofilm production is associated with higher mortality in patients with candidaemia. Mycoses. 2020;63(4):352-60.

20. Tande AJ, Gomez-Urena EO, Berbari EF, Osmon DR. Management of prosthetic joint infection. Infect Dis Clin N Am. 2017;31(2):237-52.

\section{Publisher's Note}

Springer Nature remains neutral with regard to jurisdictional claims in published maps and institutional affiliations.

Ready to submit your research? Choose BMC and benefit from:

- fast, convenient online submission

- thorough peer review by experienced researchers in your field

- rapid publication on acceptance

- support for research data, including large and complex data types

- gold Open Access which fosters wider collaboration and increased citations

- maximum visibility for your research: over $100 \mathrm{M}$ website views per year

At $\mathrm{BMC}$, research is always in progress.

Learn more biomedcentral.com/submissions 